\title{
OLHARES CRUZADOS: DO ESPELHO À IDENTIFICAÇÃO?
}

Ana Clara Torres Ribeiro In memoriam

\begin{abstract}
"Falar do futuro da urbanização e das cidades é coisa temerária. Mas não falar sobre o futuro é deserção. Não se trata do futuro como certeza, porque isso seria desmentir a sua definição, mas como tendência" (Milton Santos A urbanização brasileira, pág. 129).
\end{abstract}

Artigo recebido para publicação em 31/05/2018 e aceito em 15/06/2018

DOI: $10.12957 /$ tamoios.2018.36146

\section{INTRODUÇÃO: TENDÊNCIAS DA URBANIZAÇÃO}

É impossível iniciar esta exposição sem fazer referência à origem colonial do país e aos anseios de modernidade da sociedade brasileira. A origem colonial manifesta-se na força da urbanização litorânea e ao longo do curso dos rios. Já os anseios de modernidade estão diretamente relacionados com a intensidade e a escala do fenómeno urbano, a sua estrutura e a sua dinâmica. A macro urbanização brasileira expressa os determinantes da modernidade tardia e do capitalismo periférico, altamente concentrador das condições gerais da produção capitalista e aderente às inovações técnicas e culturais de última geração. O próprio ritmo da inovação e das mudanças culturais não se encontra determinado internamente ao país: mas, sim, sujeito à concorrência e à competitividade intercapitalistas instauradas na escala mundial.

$\mathrm{O}$ anseio por modernidade, que é correlato do anseio por soberania, orientou sucessivas ondas modernizadoras, em diversos contextos construídos pelas variações conjunturais da economia mundial e da própria composição interna das forças económicas e políticas. É frente a estas variações que pode ser identificada a diferente capacidade de alcance de adesão política por chamamentos nacionalistas e por prática de planejamento territorial. Em momentos de maior densidade destes chamamentos, acentuaram-se as estratégias propícias à construção do mercado na escala nacional; intemalização dos circuitos produtivos e à difusão de formas planejadas de controle e direcionamento da evolução urbana. Noutros momentos, porém, predominou o uso extemalizado do território, instaurando segmentos de uma rede urbana basicamente voltada à extroversão da riqueza.

Resulta das estratégias e dos modelos acionados na modernização da sociedade brasileira, ao longo do século XX, uma urbanização que expressa diferentes níveis, densidades e tempos do planejamento económico e urbano e, ainda, diferentes aproximações com paradigmas da cidade moderna. Assim, a rede urbana brasileira inclui desde as capitais totalmente planejadas do Centro-Oeste, onde a pobreza também é intensa e confronta ideários do urbanismo, até as capitais nacionais, com laivos de cidades globais, do Sudeste (São Paulo e Rio de Janeiro).

Inclui, também, as cidades que hoje eclodem, no Centro-Oeste, em articulação com o avanço dos investimentos transnacionais no agrobusiness e aquelas outras capitais que envelhecem por perda de funções administrativas e sua pouca relevância na dinâmica espacial da nova economia. Basta citar, nesta direção, as diferenças hoje observadas entre os ritmos de crescimento económico e demográfico do Recife e de Fortaleza no nordeste do país ou, entre a intensa dinâmica do interior do Estado de São Paulo e a perda de ritmo de crescimento económico e demográfico da própria metrópole paulista. 
As dimensões territoriais do Brasil e as suas diferenças regionais, da mesma forma que os papéis e funções histórica e atualmente exercidos pela rede urbana frente a dinâmica da economia nacional e mundial, impossibilitam leituras simples da urbanização e da pobreza. De fato, existem diferenças de tempos históricos que impedem esta leitura, como afirmou José de Souza Martins no livro Fronteira: a degradação do Outro nos confins do humano. Também existem diferenças étnicas e culturais que tomam estas leituras frágeis e equivocadas. Cada vez mais verifica-se a complexidade do fenómeno urbano no país e, assim, a dificuldade enfrentada por análises que pretendam articular urbanização e tendências da economia.

Os equívocos da leitura homogénea e homogeneizadora do fenómeno urbano surgiram naqueles estudos que apostaram na capacidade transformadora e alisadora de territórios e culturas do próprio capitalismo e naqueles outros estudos que, apoiados na economia, sustentaram metas unívocas para a modernização do país, omitindo a capacidade concentradora do próprio capital e os encadeamentos entre lugares que possibilitam a sucção e o direcionamento da riqueza produzida para os centros gestores da economia mais avançada em termos técnicos e financeiros.

Os equívocos da homogeneização hoje se repetem através dos instrumentos da denominada, por Henri Lefebvre, interpretação socio-técnica da vida social. Estes instrumentos, apoiados apenas estatísticas e modelagens da pobreza, reforçam a calculabilidade e a racionalidade instrumental que caracterizam a última modernidade. Há, portanto, uma nova frente gestora das relações Sociedade-Estado, em apoio à definição de estratégias de combate à pobreza e de metas de desenvolvimento social. A capacidade de convencimento desta frente secundariza os esforços dirigidos ao mapeamento da nova divisão social e territorial do trabalho e, assim, de novos sentidos da experiência urbana.

Os instrumentos acionados nesta frente permitem reconhecer a invariância e a similitude e, também, medir diferenças quantitativas entre famílias e lugares, como exemplificam a linha da pobreza e o IDH; porém, estes instrumentos não permitem valorizar a heterogeneidade, a diversidade e as diferenças espaço-temporais e culturais que marcam a urbanização brasileira e, assim, a própria experiência da pobreza. As características físicas dos lugares não bastam para o reconhecimento de seus conteúdos sociais, políticos e culturais. Da mesma forma, as intervenções no espaço físico, como sabe-se, não garantem, por si sós, a redução das desigualdades sociais.

Como tratar com os mesmos instrumentos a pobreza, e a riqueza, nas cidades indígenas da Amazónia, como as denominou Edna Castro; na Roma negra que é Salvador; na rede urbana de origem colonial da serra gaúcha (italianos e alemães); na metrópole multicultural e multinacional que é São Paulo ou, ainda, na mescla quase caribenha do Rio de Janeiro? Como disse Alain Badiou, não é possível (ou não deveria ser possível, melhor dizendo) pensar da mesma maneira em lugares tão diferentes.

\section{RECONHECENDO O OUTRO E O DIVERSO}

No entanto, tem sido possível impor o mesmo diagnóstico, a mesma forma, a mesma orientação administrativa ou as mesmas formas de intervenção aos mais diferentes lugares, desconhecendo diferenças regionais positivas e a riqueza da diversidade cultural que caracteriza o país. Talvez, como disse Moniz Sodré em programa transmitido pela TV Cultura, falte o fundamental para a superação de preconceitos e estereótipos e, aqui acrescenta-se. para que a experiência urbana contenha o respeito e o diálogo com o Outro - a afetividade. Sem a afetividade, o Outro é apenas a precariedade material das suas condições urbanas de vida. 
O predomínio da razão, que orientou a parcial conquista da cidade moderna no Brasil e os caminhos percorridos para o enfrentamento da pobreza e das desigualdades sociais, gerou o abandono dos percursos oferecidos pelo afeto e pela emoção, assim como, orientações baseadas na empatia e na identificação com o Outro. Por este motivo, os resultados alcançados são tão claramente limitados e excludentes, correspondendo à reprodução amplificada da pobreza e da miséria. Por este mesmo motivo, reproduz-se, com extrema facilidade, a oposição entre civilização e barbárie (ou anomia) na interpretação do urbano.

As relações entre magnitudes e características qualitativas da pobreza desafiam o analista da sociedade brasileira, além da instabilidade, que ainda permanece, do fenómeno urbano. Por exemplo, algumas metrópoles recentemente institucionalizadas não apresentam uma densidade populacional especialmente significativa para o contexto brasileiro, como é o caso de metrópoles do Estado de Santa Catarina. Já outras, após décadas de intenso crescimento populacional, parecem ter atingido o seu auge, começando a experimentar o descenso.

Nesta última direção, pode ser referido o ritmo mais agudo de crescimento demográfico das metrópoles de Santos e Campinas do que o observado, nas últimas décadas, na metrópole de São Paulo. Em idêntico sentido, pode ser aqui citado o menor ritmo de crescimento da cidade do Rio de Janeiro do que o verificado, no mesmo período, em algumas cidades da periferia metropolitana. Não se trata apenas, para esta última metrópole, de crescimento demográfico periférico expressivo da expulsão de população do município-núcleo e da densificação de cidades-dormitórios; mas, também, de um novo dinamismo económico na periferia metropolitana, baseado em investimentos privados e dos governos estadual e federal.

Estes fatos correspondem ao fenómeno mais amplo que Milton Santos denominou de involução metropolitana. Este fenómeno condensa diversos e complexos processos, tais como: impactos da reestruturação produtiva e da precarização das relações de trabalho; desindustrialização e/ou deslocamento espacial dos investimentos produtivos; difusão do novo meio geográfico (composto por tecnologias de informação e comunicação), permitindo a desconcentração de atividades de comando; crescente relevância das corporações transnacionais, cuja atuação em grande parte independe das condições de produção oferecidas por municípios-núcleos das metrópoles históricas.

A involução, com os seus processos intrínsecos, cada vez mais emerge como urbanização dispersa. Esta manifestação singular da urbanização - associável à americanização da experiência urbana e à globalização económica - afirma-se como uma relevante tendência do presente. São alguns dos processos que alimentam (e expressam) a urbanização dispersa: em primeiro lugar, o aparecimento de uma periferia rica nas principais metrópoles do país, como estudado por Heloisa Costa para Minas Gerais, e por Simone Polli, para o caso de Curitiba.

A afirmação desta periferia, formada por condomínios fechados e serviços privados excepcionais, pressiona as áreas da pobreza, ameaçando a permanência de segmentos populares, por vezes pioneiros nestas áreas, pelo aumento do preço da terra e, ainda, pelo recurso à face repressora do Estado, facilmente acionável pelos mais ricos. Esta é uma tendência expressiva das novas formas assumidas pela produção imobiliária, agora animada por vetores da modelização formados pela associação entre capital financeiro e capital imobiliário. Trata-se de uma produção imobiliária apoiada em serviços terceirizados e práticas administrativas que garantem o sobrelucro, reservado aos novos pioneiros, e o lucro contínuo, ligado à oferta de serviços permanentes.

Outro processo, que precisa ser aqui citado, é a turistificação do território. Este processo adquire características especialmente cruéis quando existe grande diferença de 
renda entre turistas e população local. O estímulo ao turismo, que tem acompanhado os financiamentos internacionais de políticas urbanas, gera grande impacto econômicocultural em lugares com raras amenidades ou com patrimônio histórico significativo. Existem riscos crescentes de desapropriação de territórios populares, onde a pobreza não se confunde, ainda, com a miséria. Em situações de extrema carência de renda, os investimentos económicos geram facilmente a desterritorialização dos mais pobres.

A força e os sentidos dos impactos do turismo, produtor de cisões sociais e de fragmentação territorial, foram estudados por Marina Xavier no que concerne o exemplo de Búzios, no Estado do Rio de Janeiro. A área privilegiada de Búzios é hoje praticamente um território segmentado do seu entorno, onde se concentram os mais pobres. Também Carmem Beatriz Silveira estudou os efeitos segregacionistas dos elos, associados ao turismo, entre políticas culturais e urbanas na cidade do Rio de Janeiro.

Ainda outro processo expressivo da urbanização dispersa pode ser reconhecido no que denominamos de colonização da rede urbana. Com este conceito, salientou-se a expansão de redes padronizadas de serviços na rede urbana do país, rompendo a originalidade dos lugares e permitindo a difusão de estilos de vida característicos das metrópoles dos países centrais ou das grandes cidades brasileiras. Trata-se de um novo ativismo, empreendedor, que compete com formas tradicionais de produção, de consumo e de manifestação da sociabilidade.

Assim, a urbanização dispersa, apoiada em novos meios e formas de metropolitana. São exemplo deste fenómeno: a emergência de novos centros financeiros e administrativos, desconectados da pobreza e da história do lugar; a tendência à perda de relevância e de funções dos centros históricos; a crescente privatização do espaço público, justificada pelo aumento da insegurança e pela necessidade de favorecer o turismo; o esgotamento dos lugares de moradia e das estratégias tradicionais de sobrevivência do pobre urbano, incluindo as suas formas de fazer política; a aguda periferização e a radicalização do imobilismo dos mais pobres; a fragilização da sociabilidade interclassista; a elitização do mercado de trabalho urbano, com a segregação dos setores populares das oportunidades de trabalho abertas pelos novos serviços.

\section{A CIDADE OCIDENTAL: OS LIMITES DO MODERNO}

A força destes novos fenómenos e processos - urbanização dispersa, involução metropolitana e involução intra-metropolitana - indica, até certo ponto, o potencial esgotamento da cidade ocidental e do olhar eurocêntrico, que orientaram os anseios e os modelos/projetos de modernidade e de modernização no país. A cidade ocidental explode, agora, sob os impactos fragmentadores dos impulsos globais, ou das verticalidades como disse Milton Santos, enquanto o olhar eurocêntrico é contrarrestado pela própria americanização da experiência urbana, correlata às pressões da urbanização dispersa e ao aparecimento, nas grandes cidades europeias, de questões sociais indicativa de que a periferia também habita o centro. Emergem, portanto, novas relações centro-periferia em todas as escalas do fenómeno urbano e novos híbridos espaciais e sócio-culturais.

A grande cidade e o urbano em geral constituíram por longos anos, no Brasil, os verdadeiros epicentros dos projetos de modernidade e modernização, por confrontarem a reprodução de relações sociais, oligárquicas e tradicionais, que marcaram o campo. $\mathrm{O}$ campo significou historicamente (e, ainda, em parte significa) o atraso, a reprodução de formas arcaicas de trabalho e a dependência económica no plano da divisão internacional do trabalho.

As grandes cidades brasileiras constituíram, em contraste com esse campo, a vitrine do moderno, do nível de modernidade alcançável pelo país, ainda que a 
modernidade, com os seus conteúdos de cidadania, tenha sido alcançada apenas por alguns. Trechos de Europa, dos quais foram retirados os pobres, inscreveram-se na materialidade urbana, assim como, hábitos, costumes, códigos urbanísticos e formas de consumo.

À influência europeia alimentada pelas pretensões universais do urbanismo e do direito, mesclou-se a influência norte-americana, cada vez mais atuante nas últimas décadas por corresponder aos seletivos processos de difusão do novo meio geográfico e à organização financeira da nova economia. É indispensável acentuar a face elitista do moderno na experiência brasileira, associada aos limites da acumulação capitalista e, portanto, do próprio mercado urbano; ao peso da herança escravocrata recente e ao poder de determinação, dos usos do espaço urbano, de regras e normas relacionadas a uma rígida (e resistente) estratificação social.

Os sentidos culturais e econômicos desses processos podem ser reconhecidos nas extraordinárias desigualdades espaciais que marcam a fisionomia e a paisagem das grandes cidades brasileiras. Estas desigualdades emergem como favelas no Rio de Janeiro; como mocambos em Recife; como precários loteamentos periféricos em São Paulo; como invasões em Salvador. Talvez possa ser dito, por fim, que o fato mais exemplar da reprodução ampliada destas desigualdades seja a intensa favelização observada na cidade de São Paulo e, também, a favelização na periferia do Rio de Janeiro.

Os limites do moderno, agora alimentados pela arquitetura de griffe e por centros de lazer espelhados e nos últimos modelos para a gestão urbana, surgem, sem dúvida, da cidade não planejada e nem desejada, da outra cidade, ou melhor, da cidade popular. Nas últimas décadas, eivadas de apelos à moda na produção do espaço urbano, a vitrine constituída pelas áreas que concentram os investimentos em tecnologia e prazer tem sido completada por novos referentes culturais, como exemplificam o imaginário do campo moderno, a cultura country e as espacialidades próximas da primeira natureza trazidas pelos meios de comunicação através da ênfase no ecoturismo e no esporte de aventura.

Para a alimentação deste imaginário, não são necessários apenas os edifícios muitíssimo altos ou os planos vazios (e estéreis) dos museus e centros culturais, tão amplamente associados aos produtos financeiros e midiáticos. São indispensáveis, em acréscimo, os condomínios que privatizam a primeira natureza, em nome da sua preservação; os exemplos de artistas que ff se transformam em eficazes criadores de gado ou proprietários de haras e, ainda, a fartura, propiciada pelo marketing, de silhuetas perfeitas em associação com grandes fazendas australianas ou com as ondas do Hawaii.

Nestas circunstâncias, o urbano genérico, com suas novas qualidades segregacionistas, afirma-se como aceleração da vida dos mais ricos e como estagnação da vida dos mais pobres e miseráveis. Nada melhor para exemplificar este fato do que o contraste formado entre os helicópteros, que se multiplicam na cidade de São Paulo, e o simultâneo aumento daqueles que circulam a pé ou de bicicleta. Este não é um cenário bucólico. Ao inverso, é um cenário onde afirma-se a apartação social e onde a co-presença toma-se cada vez mais impossível. Os carros blindados, os serviços privados de segurança e os vidros escurecidos de tantos automóveis são outras tantas manifestações dos mesmos fenómenos: a involução metropolitana e intrametropolitana.

A cidade antes epicentro da modernidade e dos projetos de modernização das sociedades periféricas submerge, de um lado, pela atual afirmação de projetos urbanos pontuais ou da denominada acupuntura urbana, mais estética do que estruturadora. Submerge, também, sob uma dupla pressão imaginária e imagética: de um lado, o imaginário futurista de uma vida altamente privada, consumida por tecnologias de ponta que substituem os deslocamentos e os encontros face-a-face. E, de outro lado, as imagens 
e o crescente evidência de um período no qual a violência manifesta-se sem descanso e de forma cada vez mais próxima, banal e destrutiva.

A incapacidade do Estado em lidar com as características deste período surge em sua adaptação à própria violência, seja através de medidas paliativas como a não cobrança ou a redução de IPTU em áreas submetidas ao comando do tráfico de drogas, seja através da ampliação da própria violência, em associação (ou não) com os interesses do tráfico. Tomam-se nítidas, no presente, a desqualificação e a desproteção das históricas conquistas, alcançadas com elevados custos sociais, do "direito à cidade" pelas classes populares.

Essa desqualificação e essa desproteção materializam-se na morte de jovens e crianças e, através em intervenções, nas áreas populares, que militarizam, também violentamente, o cotidiano. O imaginário da guerra, estimulado pela cena mundial e pela mídia, alimenta o confronto armado nas áreas populares, destinado os sentidos integradores dos investimentos em políticas sociais: saúde, educação, cultura. Especulariza-se a morte, por curtos instantes, pela apropriação circunstancial da própria plasticidade dos protestos populares, que envolvem por vezes a interrupção da circulação urbana e a queima de pneus e veículos, retomando, no momento seguinte, a mesma situação anterior: ameaçadora, segregada e incerta.

Recorrendo às metáforas do sangue e da pedra, tão utilizadas na reflexão da cidade, poder-se-ia dizer que, atualmente, esta dialética encontra-se tendencialmente interrompida, a não ser nas áreas urbanas que recebem os investimentos, de último tipo, em cultura, serviços e lazer. Nas áreas populares, sangue e pedra aproximam-se rapidamente do acontecimento e do instante, transformados em "sempre mais do mesmo". Enfrenta-se hoje uma multidimensional crise societária, cujas consequências mais agudas concentram-se nas áreas populares, aqui denominadas de "zonas desfavorecidas".

No Rio de Janeiro, a longa história desse desfavorecimento, ou seletividade social, em grande parte oculta por não corresponder aos interesses daqueles que usufruem da concentração dos investimentos públicos, recebe hoje os custos da economia clandestina que alimenta, de forma não dita, circuitos da riqueza estimuladores da cidade-espetáculo. Existem novas passagens e elos entre riqueza e pobreza, como não poderia deixar de ser, demonstrando os limites das análises dicotómicas e simplistas. Afinal, atualmente, a fragmentação não é apenas um fato ou fatalidade. É também projeto e projeção da vida urbana.

Existem, nos cenários fragmentados e fragmentadores da última modernidade, experimentos de novas relações interclassistas, concretizados sobretudo pela juventude, e um ativismo que envolve novos atores sociais e políticos. Além do tráfico de drogas, as áreas populares têm sido ocupadas por investimentos públicos, ainda que pequenos, e iniciativas culturais; por igrejas evangélicas e ONGs; por cooperativas populares e investimentos em economia solidária; por partidos políticos, ações institucionais e novas formas de assistencialismo.

Não se trata, portanto, de uma realidade morta, de uma espécie de involuntária mimese popular do isolamento ansiado pelas classes média e alta; mas, ao contrário, de uma realidade profundamente ativa e com clara capacidade propositiva, como demonstra o fato de que parte das políticas urbanas destinadas às áreas populares tenha tido a sua génese em históricas resistências sociais. Cite-se, nesta direção, o programa FavelaBairro e a intensa interação com redes sociais, a luta por oportunidades de acesso à renda e a multiplicação das ações culturais, como as desenvolvidas pelo Observatório das Favelas.

As características da última modernidade, fragmentadora e espetacular, instalamse sobre acúmulos de desfavoreci mentos e esquecimentos pretéritos, exigindo a leitura 
de uma sucessão de seletividades sociais e resistências coletivas. Estas características não admitem leituras teleológicas fáceis, com tantas vezes feito pelo pensamento crítico. A consciência da marginalização, da exclusão e da guetificação, alimentada pelo acesso às novas redes técnicas, eclode através de uma plural e rica produção cultural de novo tipo. ídolos, protagonistas e estilos próprios das áreas populares indiciam a afirmação de um novo poder de iniciativa, cujos sentidos e potencialidades precisam ser reconhecidos pelos analistas do urbano.

Não se trata de apostar, apenas, na extensão da institucionalidade dominante aos lugares da pobreza, da miséria e da exclusão, como se esta institucionalidade expressasse o modelo desejado (e desejável) para a vida urbana. Trata-se, ao contrário, de reconhecer a diversidade da experiência urbana, investindo num novo imaginário institucional, que seja capaz de reconhecer os valores, as conquistas, a legitimidade e as carências do Outro. Há uma outra urbanidade latente no presente, contra restada pela cidade espetáculo e pelo aumento da violência diária.

\section{OLHAR EUROCENTRICO E A NOVA EPISTEME}

Entretanto, existe um obstáculo epistemológico na leitura da experiência urbana brasileira e de outros países periféricos, que se agrega à magnitude atingida pela crise societária. Sem dualismos de qualquer tipo, é necessário reconhecer as singularidades do fenómeno urbano na experiência brasileira. Diferentes modelos e projetos, parcialmente realizados, convivem na configuração desta experiência, com seus extensores para uma realidade popular não planejada ou apenas submetida, superficialmente, às normas do planejamento. A não aplicação destas normas, ou a sua contínua negociação, bem indica a acomodação da ação do Estado à realidade imediata e à urgência social.

É por esta razão que as ciências aplicadas ao urbano, com forte teor eurocêntrico, fornecem apenas limitadas interpretações da grande cidade periférica. Mesmo a reflexão crítica dirigida a determinadas disciplinas, tais como o urbanismo e a economia urbana, fornece explicações apenas para segmentos escolhidos da realidade urbana, apresentando claros limites para a análise da totalidade em movimento, em seus diferentes ritmos internos. Esta totalidade remete à experiência urbana do capitalismo tardio, que subordina o Estado a um forte ativismo em direção ao desenvolvimento econômico.

Aqui não se faz nenhum tipo de adesão às teorias da urbanização excessiva ou da hiperurbanização do país, já amplamente críticas por tantos analistas; mas, apenas constata-se a saga brasileira, marcada por fortíssimos desenraizamentos associados aos impulsos ao moderno. Nestas circunstâncias, o urbanismo e o planejamento urbano são constantemente "adaptados" ao real, através de concessões na legislação urbanística e de uma espécie de cegueira estrategicamente aplicada à realidade imediata.

Para aqui lembrarmos Saramago, e contando com esta cegueira, correlata de uma contraditória lucidez, e com mediações políticas subaltemizantes, que sobrevive (e se expande) a cidade popular. Seus códigos e espaço internos tem sido adaptado, ainda que fragilmente, e através de múltiplas acomodações, às normas dominantes, até mesmo como condição para a outorga de investimentos públicos. Os limites destes investimentos, juntamente com os limites no acesso à renda, geram o cenário da "viração", no qual a ilegalidade aceita constitui o terreno propício ao abuso e à violência.

$\mathrm{Na}$ adaptação das normas dominantes, muitas vezes acontece, como analisado por Lenise Femandez, a desapropriação política e simbólica de conquistas populares. Esta adaptação constitui-se, de fato, como um trabalho de Sísifo, realizado pelas classes populares, pela assessoria prestada por diferentes instituições e pelo Estado. Pode ser prevista, desde já, a permanência deste trabalho no futuro próximo, na medida em que 
não sejam radicalmente reduzidas as desigualdades sociais no acesso à renda e à terra urbanas. Deste trabalho, saem perdedoras as classes populares no que concerne a afirmação de sua identidade política. Também sai perdedor o Estado, na medida em que a sua intervenção não garante a integração social e nem o funcionamento estável dos serviços urbanos.

Aceita-se a ilegalidade ou a para-legalidade simplesmente porque não há alternativas e nem a concreta possibilidade, até o momento, de uma cidade para todos. Nesta direção, poder-se-ia dizer, em resposta à pergunta uma vez formulada por Milton Santos - por que as favelas não explodem? - que as favelas são extraordinárias conquistas populares; cabendo indagar as razões de sua limitada expansão como forma coletiva de vida. Não teria sentido, portanto, expirar por sua explosão. Na mesma direção, seria possível acrescentar que as formas subaltemizantes de negociação e acomodação também colaboram para que esta explosão não aconteça...

Por outro lado, afirmar que as favelas representam a solução para a habitação popular também não se justifica, já que isto significaria ignorar sua precariedade, os seus sentidos para aqueles que as construíram e, também, desconhecer os cruéis mecanismos da espoliação urbana, favorecendo a continuidade da concentração dos investimentos públicos nas áreas privilegiadas das grandes cidades brasileiras.

Sem permitir a idealização da pobreza e da miséria, em nome do reconhecimento do Outro e de suas conquistas, é necessário, hoje mais do que nunca, identificar as potencialidades das propostas populares para a vida urbana. Para isto, é indispensável superar tanto as leituras piegas quanto minimalistas da experiência popular, através do desvendamento de uma nova episteme. Esta espísteme, necessariamente dialógica, precisará superar as falsas fronteiras (barreiras) entre favela e asfalto; entre disciplinas sociais, entre estas e as artes e, ainda, entre as ciências sociais e os saberes do Outro.

É necessário desvencilhar as propostas que advém da experiência popular dos impactos negativos dos limites económicos e mecanismos de controle que a contiveram e subordinaram até agora. Não se propõe, portanto, o elogio do "pequeno" e do "simples" ou, ainda, do capital social envolvido na construção da cidade popular, a serem potencialmente incorporados em políticas urbanas de baixo custo. Mas, sim, defende-se a dignidade do Outro e, mais, de suas conquistas e vitórias. Cabe, portanto, reconhecer a sua força e não apenas as suas carências e necessidades.

Falta, e muito, um diálogo intersubjetivo que ultrapasse o bom tom dos discursos regrados e os ideários da classe média, tão intensamente nutridos pelo olhar eurocêntrico e por propostas clean das cidades norte-americanas, em seus elos dinâmica com a urbanização dispersa. Isto significa dizer que é necessário favorecer propostas práticas da cidade popular, como faz Paola Berenstein Jacques ao reconhecer a ginga das favelas. Nos labirintos (que não precisariam ser miseráveis e sem saneamento) sempre couberam muitos, como demonstram tão bem as formas sobreviventes das cidades medievais, diferentemente do observado nos salões e jardins dos castelos (velhos e novos).

Nos labirintos que também são construídos pelas práticas da economia popular nas áreas modernas da grande cidade periférica, como demonstra o comércio de rua, manifestam-se o compartilhamento de recursos materiais, a solidariedade e as táticas que garantem a sobrevivência em contextos adversos. Este é um outro urbanismo, ou melhor, o urbanismo e a arquitetura do Outro, nas suas atuais condições de contenção e subalternidade. Estas são outras formas, orgânicas e tentativas, que podem vir a orientar a reflexão da arquitetura, do planejamento urbano e do urbanismo numa época de incertezas radicais.

É claro que esta indicação não corresponde, mais uma vez, a um irresponsável elogio da precariedade; mas, à retirada de ensinamentos das práticas do Outro. Acredita- 
se que estes mesmos ensinamentos adquirem, no presente, novas conotações, como indicam as seguidas ocupações de prédios públicos e privados em áreas centrais das metrópoles brasileiras. Há uma centralidade popular a ser reconhecida, sistematizada e favorecida, num período em que se esgotam as referências materiais e subjetivas da modernidade.

A última modernidade ou a modernidade radicalizada, como Giddens nomeou o atual período histórico, é sobretudo um momento em aberto, no qual a própria herança da modernidade tem sido interrogada, da mesma maneira que as ciências e as formas de manifestação artística que nela surgiram e se afirmaram. Hoje, o Outro não planejado supera as tentativas de planejamento do Outro aceito e aceitável, procurado em tantas políticas o Outro rejeitado. Atualmente, contata-se o predomínio da arquitetura sobre o urbanismo racionalista; da gestão sobre o planejamento; da imagem sobre a infraestrutura; do empreendedorismo sobre a indústria. Existem menos recursos para a manutenção das grandes cidades e, cada vez mais, a própria preservação de seu dinamismo económico transforma-se em questão enfrentada pelo poder local. Neste contexto, busca-se orientações urbanísticas e administrativas que viabilizem a acomodação da pobreza e da miséria, agora esperadas e até mesmo tidas, em grande parte, como irreversíveis. Mas, nem sempre foi assim...

No caso brasileiro, o pobre urbano é, sobretudo, o Outro não desejável, por excessivo e economicamente desnecessário. Inclusive nos momentos de mais intensa industrialização, dificilmente pode ser afirmado que todos os pobres constituíram, de alguma forma, o exército industrial de reserva. A marginalidade social e a denominada economia informal, portanto, não são somente frutos dos avanços tecnológicos, que poupam força de trabalho numa escala antes desconhecida, e nem da gestão financeira que caracteriza a atual fase do capitalismo. Mas, ao contrário, são fenómenos estruturais e, assim, intrínsecos à experiência urbana consolidada ao longo do século XX, sobretudo em sua manifestação metropolitana. Havia pouco capital para o urbano, como disse Francisco de Oliveira, e este foi concentrado no estímulo à acumulação e, poderíamos acrescentar, no alcance da seletiva paisagem da cidade moderna, civilizada.

Assim, o capital público foi utilizado para afirmação da cidade burguesa, em São Paulo, Rio de Janeiro e outras capitais que se destacaram no século passado. Pelos limites desta burguesia, a cidade moderna adquire laivos aristocráticos, criando distâncias sociais que se materializam na paisagem urbana. São exemplos: a zona sul do Rio de Janeiro e os jardins paulistanos. Desta maneira, pode ser afirmado que a exclusão social trazida pelo atual metabolismo do capital, ainda mais dura nos países que não comandam a economia-mundo, afuma-se sobre uma base sócio-espacial formada por mecanismos reprodutores da marginalização social e da espoliação urbana, como afirmou Lúcio Kowarick, dos mais pobres; espoliação que envolve o I pagamento, inclusive pela saúde, do "estar na cidade" e o trabalho não pago na produção da habitação e, também em numerosos casos, na produção da própria terra urbana, como exemplificam os bairros construídos em encostas (áreas de risco) e através da conquista de margens da Baía da Guanabara. A marginalização e a espoliação nos dizem da experiência urbana do Outro não esperado e para o qual o planejamento basicamente não existiu. A presença popular, nas metrópoles brasileira, é fruto de resistências e conquistas sociais, em decorrência dos incertos e baixos salários, impeditivos da poupança popular a não ser através da habitação gradualmente construída; dos custos da habitação pela excepcionalidade da terra equipada; dos limites das políticas habitacional e urbana, analisados por Nabil Bonduki, que atenderam, somente, alguns segmentos da classe trabalhadora e a classe média.

$\mathrm{Na}$ experiência brasileira, a expansão do moderno mercado de bens e serviços foi sempre acompanhada da configuração de mercados outros, paralegais e informais, 
voltados ao atendimento das carências das classes populares. Existiram, sim, programas habitacionais de inspiração modernista; mas, estes foram exceção numa experiência urbana apoiada em precários loteamentos periféricos, invasões e favelas. A própria execução destes programas - na forma de conjuntos habitacionais periféricos - é expressiva da recusa da cidade popular. Sem dúvida, as relações natureza e sociedade, da mesma maneira que as relações campo e cidade, adquirem novos conteúdos no presente; introduzindo riscos de naturalização das relações sociais no próprio âmago da experiência urbana. Estes riscos transformam o campo, tecnologicamente moderno e logo humanamente esvaziado, em expressão privilegiada do urbano genérico. Cópias reduzidas deste campo aparecem, no presente, ao longo da rede urbana, na forma de condomínios fechados e de estradas exclusivas. O que esperar para as metrópoles históricas? Estará chegando o tempo de afirmação da cidade popular? 